\title{
Bundle pricing of inventories with stochastic demand
}

\author{
Zümbül Bulut ${ }^{\mathrm{a}}$, Ülkü Gürler ${ }^{\mathrm{b}}$, Alper Şen ${ }^{\mathrm{b}, *}$ \\ ${ }^{a}$ Department of Industrial and Systems Engineering, Lehigh University, 200 W. Packer Avenue, Bethlehem, PA 18015, USA \\ ${ }^{\mathrm{b}}$ Department of Industrial Engineering, Bilkent University, Bilkent, 06800 Ankara, Turkey
}

Received 5 January 2006; accepted 28 September 2006

Available online 21 February 2008

\begin{abstract}
We consider a retailer selling a fixed inventory of two perishable products over a finite horizon. Assuming Poisson arrivals and a bivariate reservation price distribution, we determine the optimal product and bundle prices that maximize the expected revenue. Our results indicate that the performances of mixed bundling, pure bundling and unbundled sales strategies heavily depend on the parameters of the demand process and the initial inventory levels. Bundling appears to be most effective with negatively correlated reservation prices and high starting inventory levels. When the starting inventory levels are equal and in excess of average demand, most of the benefits of bundling can be achieved through pure bundling. However, the mixed bundling strategy dominates the other two when the starting inventory levels are not equal. We also observe that an incorrect modeling of the reservation prices may lead to significant losses. The model is extended to allow for price changes during the selling horizon. It is shown that offering price bundles mid-season may be more effective than changing individual product prices.
\end{abstract}

(c) 2008 Elsevier B.V. All rights reserved.

Keywords: Pricing; Revenue management; Bundling

\section{Introduction}

Bundling is the practice of selling two or more products together. Companies engage in bundling in a wide range of industries including information goods (e.g., software such as Microsoft's Office Suite), travel services (e.g., vacation packages from travel agencies), restaurants (e.g., McDonald's Happy Meal), durable consumer goods (e.g., personal computer options) and non-durable consumer goods (e.g., dishwasher detergent and rinse aid packages). Bundles are offered for a variety of reasons. Strategically, a company may use bundling to preserve (or increase) market power, or to extend its market power in one product to another. Efficiency reasons include achieving cost savings and quality improvements and reducing pricing inefficiencies. See Nalebuff (2003) for a detailed discussion of the motivations to engage in bundling.

\footnotetext{
* Corresponding author. Tel.: +90 312290 1539; fax: +90 3122664054.

E-mail addresses: zub205@lehigh.edu (Z. Bulut),ulku@bilkent.edu.tr (Ü. Gürler), alpersen@bilkent.edu.tr (A. Şen).
}

The advancement of the Internet and other information technologies has brought the practice of bundling to a new frontier. An enormous amount of detailed consumer buying behavior data are now available, and the E-tailers are able to make bundling and pricing decisions in a costless and timely manner. According to a survey by E-tailing Group Inc., $88 \%$ of top 100 online retailers suggest additional products on their websites (E-tailing Group (2004)). For example, a customer who intends to buy the latest R.E.M. album "Around the Sun" for $\$ 13.49$ or "At the Organ" album from The Minus 5 for $\$ 10.99$ from Amazon.com will be offered to buy them together at a discounted price of $\$ 22.48$. Note that the online retailer does not always need to offer a discount on the bundle, as the shipping costs are almost never linear (Amazon.com charges $\$ 2.98$ for a single CD, $\$ 3.97$ for two CDs for standard shipping to US customers). Bundling or cross-selling is also very popular for books, music, electronics and apparel and accessories, and online travel service providers. 
While there is a significant adoption of bundling practices in the industry, there are also serious challenges for companies that consider implementation of bundling. First, the benefits of bundling need to be quantified in order to see whether the benefits justify the potential costs and additional complexity in operations. Also, if the company is offering more than two products, it needs to specify the number of different bundle types to offer and what products to include in each specific bundle. For products that are sold as part of a bundle, the company also needs to decide whether it will continue to sell these products individually (i.e., mixed bundling) or not (i.e., pure bundling). Finally, the company needs to determine the bundle prices and individual product prices that will maximize its profits.

Previous research on bundling in the marketing and economics literature focuses on the identification of demand settings for which bundling is profitable. The purchase behavior of the customers is usually characterized by the reservation price (maximum price a customer is willing to pay for a product) distributions of the products. Correlation between the reservation prices, complementarity, substitutability and heterogeneity of valuations among customers are major factors in the discussion of the profitability of bundling strategies. The earliest study to address such issues is by Stigler (1963) who assumes additive reservation prices for the bundle and concludes that the profitability of bundling is due to the negative correlation in reservation prices. Adams and Yellen (1976) use the same settings as Stigler (1963) and argue that the profitability of bundling can stem from its ability to sort customers into groups with different reservation price characteristics, and hence extract consumer surplus. Considering the three bundling strategies, pure components (unbundling), pure bundling and mixed bundling, they conclude that relative profitability of these three strategies depends on the distribution of the reservation prices and the structure of the costs (see also Jeuland (1984)). In numerous experiments they have provided, it is found that some form of bundling is more profitable than simple monopoly pricing and bundling seems to be a more efficient method than price discrimination. Schmalensee (1984) modifies the framework of Stigler (1963) by assuming a bivariate normal reservation price distribution and allowing for positive correlation. $\mathrm{He}$ shows that pure bundling operates by reducing the effective dispersion in buyers' tastes, since the standard deviation of reservation prices for the bundle is less than the sum of the standard deviations for the two components as long as reservation prices are not perfectly correlated. Schmalensee (1984) also shows that mixed bundling combines the advantages of pure bundling and unbundling strategies. This policy enables the seller to reduce effective heterogeneity among those buyers with high reservation prices for both goods, while still selling at a high markup to those buyers willing to pay a high price for only one of the goods. In a comment to Schmalensee (1984), Long (1984) relaxes the normality assumption on reservation price distributions and also concludes that the most favorable case for bundling as a price discrimination device is when the bundle components have negatively correlated reservation prices. Focusing on graphical analysis of bundling, Salinger (1995) indicates that if bundling does not lower costs, it tends to be profitable with negatively correlated reservation prices that are high relative to costs. If bundling lowers costs and costs are high relative to reservation values, positively correlated reservation values increase the incentive to bundle.

Although not directly related to our study, see also Ansari et al. (1996) for the determination of the optimal number of items to be included in a service bundle, BenAkiva and Gershenfeld (1998) for customer choice behavior for bundles with correlated demand, Carbajo et al. (1990) for incentives for bundling under imperfect competition, Hanson and Martin (1990) for the calculation of optimal bundle prices in a deterministic setting, using mixed integer linear programming, Ernst and Kouvelis (1999) for the effect of selling product bundles (as opposed to price bundles in our case) on inventory decisions, and Stremersch and Tellis (2002) for a clear discussion of bundling terminology which is used in the marketing, economics and law literature in a somewhat unclear way. Finally, we note the growing literature on bundling of information goods (see, for example, Bakos and Brynjolfsson (1999)). However, the setting for the information goods is distinctly different from physical goods and most services, since the marginal costs are close to zero and inventory is almost never a constraint.

The basic assumption in the studies in the marketing and economics literature is that there is an abundant supply of the products, perhaps at a certain cost. In contrast, we assume that there is an initial inventory of items which needs to be sold over a finite horizon. As such, we follow the approach taken in the revenue management literature. See Talluri and van Ryzin (2004) and McGill and van Ryzin (1999) for reviews of revenue management research and Elmaghraby and Keskinocak (2003) for a review of dynamic pricing research and practice in this context. Inventory considerations in bundling decisions are critical in many product categories including travel services (airplane seats, hotel rooms and rental cars), event tickets, fashionable products such as apparel and accessories and high technology products. In contrast to previous research on bundling, we also explicitly model the customer arrival process and the behavior of the customers when the inventory of one of the products that the bundle is composed of runs out before the end of the horizon.

The papers that could be considered most directly related to our work in the revenue management literature are those studying multiple product revenue management problems as introduced in Gallego and van Ryzin (1997). Netessine et al. (2006) study a problem where they consider an e-commerce seller that dynamically forms and prices product or service packages. The problem is modeled as a dynamic program based on two possibilities in case of 
stock-out: an emergency replenishment of the customer's initial request or lost sales. Our model differs from Netessine et al. (2006) as we assume posted prices and we explicitly model the consumer choice given that she is given three alternatives upfront: to purchase either one of the products or the bundle or none.

The specific model that is used in this study involves two products that are sold over a finite horizon, either individually or as part of the bundle. It is assumed that the replenishment decisions for these two products are already made and no additional replenishments are possible during the horizon. The customers arrive following a Poisson process and each customer makes a purchasing decision based on her reservation prices of individual products: she either buys one of the individual products, buys the bundle or leaves without a purchase. It is assumed that the bundle does not require any physical integration of the products (i.e., price bundling as opposed to product bundling), thus a bundle purchase is possible as long as both products have positive inventory (no separate inventory is kept for the bundle). No cost is incurred for the formation of the bundle. If the inventory of one of the products is depleted, the customer has only two options: she either buys the remaining product or leaves without a purchase. The objective is to determine the individual product prices and the bundle price so as to maximize the expected revenue over the entire horizon. Although the main focus of the present study is the analysis of bundling strategies and the impact of bundling with constant prices through the selling horizon, the analysis of this single period model allows us to extend our model to incorporate price changes during the selling horizon. We therefore briefly discuss such an extension and provide the dynamic programming formulation of the problem together with a numerical example.

In a numerical study, we investigate the impact of several factors on the optimal expected revenues, prices and the amount of sales. These factors include the correlation between the reservation prices of the two products, the degree of contingency (complementarity or substitutability), the level of the initial stocks and the shape of the reservation price distributions. We also compare the performance of the mixed bundling strategy against that of the pure bundling and unbundling strategies. Our results show that bundling is most effective when the starting inventory levels are high and the reservation prices are negatively correlated. When the starting inventory levels for the two products are equal, most of the benefits of bundling can be obtained through pure bundling. When the starting inventory levels are not equal, the mixed bundling strategy clearly outperforms the other two. Our numerical study also shows that bundling is more effective when the products are more complementary and less substitutable. To the best of our knowledge, in the bundling literature only the symmetric and particularly the normal reservation prices are used. However, in practice, we may expect that, high reservation prices would have less probability than low ones, indicating a right skewed distribution. To con- form with this intuition, we investigated the bivariate gamma density for the reservation prices. It is observed that if the sub optimal prices resulting from a normality assumption are used when in fact the reservation prices are gamma distributed, there may be a significant loss in the revenues. We believe this finding is important from a managerial point of view. Finally, we extend our model to allow for price changes, and an illustrative example with a mid-season price change shows that the optimal initial price is higher than the expected mid-season price. It is also shown that offering price bundles mid-season may be a more effective mechanism than changing individual product prices.

The rest of the paper is organized as follows. Section 2 formulates the problem and introduces the model. Section 3 contains the numerical results. Section 4 extends the model to multiple periods. Section 5 concludes with a discussion of our major findings and avenues for future research.

\section{Model and analysis}

Given an initial inventory of two products and a finite selling season, we are concerned with the problem of determining prices of the bundle and the individual products so that the expected revenue over the selling season is maximized. To form a basis of comparison, we also study pure bundling and unbundling strategies.

Before discussing the details of our model, we elaborate on some of the fundamental assumptions that are used. In our model, the retailer's objective is maximizing revenue as opposed to maximizing profit. This is due to the following two assumptions. First, the initial inventory levels are treated as exogenous in our model. We assume that the ordering decisions are already made and the retailer no longer has any control over the initial inventory levels. Our model can be extended to incorporate initial inventory levels as decision variables, and this will enable the retailer to jointly optimize his ordering and pricing decisions before the season. However, note that even in this case, the retailer may find it useful to re-solve a fixed inventory version of the problem, once the order is received, since he might have more demand information after a lead time. Second, we assume that there are no variable costs during the season. In situations where the retailer has an additional cost associated with selling a product or forming a bundle, our model needs to be extended to incorporate these variable costs. Note that if the retailer can always find enough supply with zero lead time or he can always salvage the leftover inventory at its original cost, our model cannot be used. In these cases, the retailer's objective should be to maximize the profit rate as is typically done in the marketing and economics literature.

We assume that the customer preferences are governed by their reservation prices. Most commonly, the reservation price is defined as the maximum amount that a customer is willing to pay to purchase a product. We refer 
the reader to Jedidi and Zhang (2002) for estimating individual consumer reservation prices and to Jedidi et al. (2003) for capturing consumer heterogeneity in the joint distribution of reservation prices in the case of bundling. Other ways to model consumer behavior for differentiated products include multinomial logit (MNL) random utility model; see van Ryzin and Mahajan (1999) and Mahajan and van Ryzin (2001).

We first consider the case where the reservation price for the bundle is equal to the sum of the individual reservation prices. This reflects the assumption that the products are individually valued and is adopted by many authors (e.g., Adams and Yellen, 1976; Schmalensee, 1984; McAfee et al. (1989)). Guiltinan (1987) refers to this assumption as the assumption of strict additivity. Venkatesh and Kamakura (2003) relax the strict additivity assumption and allow for substitutability and complementarity. In this study we analyze these cases as well. If the products are substitutable, customers want to buy only one of them at a time. Then, a customer's reservation price for the bundle would be subadditive (less than the sum of the reservation prices). Alternatively, customers may tend to consume the two products together. These kind of products are called complementary. When products are complements, a customer's reservation price for the bundle is superadditive (more than the sum of the reservation prices).

\subsection{Problem definition}

We consider a retailer that sells two perishable products, Product 1 and Product 2. There are $Q_{1}$ units of Product 1 and $Q_{2}$ units of Product 2 and a fixed planning horizon of length $T$. At the beginning of the planning horizon, the retailer sets the price $p_{i}$ for product $i, i=1,2$. He also provides a bundle option which implies charging the customers less than the sum of the individual product prices if they buy both. That is, the individual product prices and the bundle price, $p_{\mathrm{b}}$ are determined so that $p_{\mathrm{b}} \leqslant p_{1}+p_{2}$. In this section, we assume that the initial prices remain unchanged until the end of the season which is relaxed in Section 4. It is assumed that, the retailer incurs fixed costs before the selling season. We therefore consider maximizing the revenue.

Customers arrive according to a Poisson Process with a fixed arrival rate of $\lambda$ customers/season. A customer is allowed to purchase a single product or a bundle, not both. She may also choose to leave without any purchase. We assume that the purchasing behavior of a customer is as follows: if the prices are lower than the reservation prices for more than one option, then she prefers the one which brings her the maximum surplus - the difference between the reservation price and the price. Reservation prices $R_{1}$ and $R_{2}$ are considered as random variables with a bivariate distribution with means $\mu_{1}, \mu_{2}$, standard deviations $\sigma_{1}, \sigma_{2}$ and correlation coefficient $\rho$. Let $f_{R_{1}, R_{2}}\left(r_{1}, r_{2}\right)$ denote the joint probability density function of the reservation prices $R_{1}$ and $R_{2}$ with corresponding marginals $f_{R_{1}}(x)$ and $f_{R_{2}}(x)$. For now, we assume that the reservation price, $R_{\mathrm{b}}$, for the bundle is equal to the sum of the individual reservation prices, i.e., $R_{\mathrm{b}}=R_{1}+R_{2}$. Later in Section 2.5, we relax this assumption. All the distributions are assumed to be known to the retailer.

When both products are available, an arriving customer compares her reservation prices for the individual products and the bundle with their respective prices and may take four possible actions: decides to leave without any purchase, buys Product 1 , buys Product 2 or buys a bundle, with respective probabilities, $\alpha_{0}, \alpha_{1}, \alpha_{2}$ and $\alpha_{\mathrm{b}}$. If at any point during the planning horizon, one of the products is depleted, these probabilities change. We denote by $\alpha_{1}^{\prime}$ the probability of buying Product 1, after depletion of Product 2 and by $\alpha_{2}^{\prime}$ the probability of buying Product 2 after depletion of Product 1 . In both cases the customer may leave without any purchase with complementary probabilities $\alpha_{01}^{\prime}=1-\alpha_{1}^{\prime}$ and $\alpha_{02}^{\prime}=1-\alpha_{2}^{\prime}$. Clearly, no bundle can be purchased if one of the products is not available. We first consider below the case when the retailer follows a mixed bundling strategy.

\subsection{Purchasing probabilities}

When both products are available, a customer will purchase nothing if her reservation prices for the two products and the bundle are lower then their corresponding sales prices. Hence,

$$
\begin{aligned}
\alpha_{0} & =P\left(R_{1}<p_{1}, R_{2}<p_{2}, R_{\mathrm{b}}<p_{\mathrm{b}}\right) \\
& =\int_{-\infty}^{p_{1}} \int_{-\infty}^{a_{1}} f_{R_{1}, R_{2}}\left(r_{1}, r_{2}\right) \mathrm{d} r_{2} \mathrm{~d} r_{1}
\end{aligned}
$$

where $a_{1}=\min \left\{p_{2}, p_{\mathrm{b}}-r_{1}\right\}$.

For $i=1,2$, the customer will purchase Product $i$ if her surplus (the difference between the reservation price and sales price) is positive and larger than her surplus from the other product and the bundle. Then the probability of purchasing Product 1 is given by,

$$
\begin{aligned}
\alpha_{1} & =P\left(R_{1}>p_{1}, R_{1}-p_{1}>R_{2}-p_{2}, R_{1}-p_{1}>R_{\mathrm{b}}-p_{\mathrm{b}}\right) \\
& =\int_{p_{1}}^{\infty} \int_{-\infty}^{a_{2}} f_{R_{1}, R_{2}}\left(r_{1}, r_{2}\right) \mathrm{d} r_{2} \mathrm{~d} r_{1}
\end{aligned}
$$

where $a_{2}=\min \left\{r_{1}-p_{1}+p_{2}, p_{\mathrm{b}}-p_{1}\right\}$. The probability of purchasing Product 2 is similarly obtained as

$\alpha_{2}=\int_{p_{2}}^{\infty} \int_{-\infty}^{a_{3}} f_{R_{1}, R_{2}}\left(r_{1}, r_{2}\right) \mathrm{d} r_{1} \mathrm{~d} r_{2}$

where $a_{3}=\min \left\{r_{2}-p_{2}+p_{1}, p_{\mathrm{b}}-p_{2}\right\}$.

Observing that a customer will purchase the bundle if her surplus is positive and larger than the surplus from both products, we have

$$
\begin{aligned}
\alpha_{\mathrm{b}} & =P\left(R_{\mathrm{b}}>p_{\mathrm{b}}, R_{\mathrm{b}}-p_{\mathrm{b}}>R_{1}-p_{1}, R_{\mathrm{b}}-p_{\mathrm{b}}>R_{2}-p_{2}\right) \\
& =\int_{p_{\mathrm{b}}-p_{2}}^{\infty} \int_{a_{4}}^{\infty} f_{R_{1}, R_{2}}\left(r_{1}, r_{2}\right) \mathrm{d} r_{2} \mathrm{~d} r_{1},
\end{aligned}
$$

where $a_{4}=\max \left\{p_{\mathrm{b}}-r_{1}, p_{\mathrm{b}}-p_{1}\right\}$. 
When one of the products is depleted, an arriving customer can no longer purchase the bundle. She can either buy one unit from the remaining product or buy nothing. The probability of purchasing Product 2 in the absence of the Product 1 is given by

$\alpha_{2}^{\prime}=P\left(R_{2}>p_{2}\right)=\int_{p_{2}}^{\infty} f_{R_{2}}\left(r_{2}\right) \mathrm{d} r_{2}$.

Similarly, the probability of purchasing Product 1 in the absence of Product 2 is,

$\alpha_{1}^{\prime}=P\left(R_{1}>p_{1}\right)=\int_{p_{1}}^{\infty} f_{R_{1}}\left(r_{1}\right) \mathrm{d} r_{1}$.

Since the arrival process is Poisson, the demand for the two products and the bundle while both products are available will follow independent Poisson processes with rates $\lambda \alpha_{1}$, $\lambda \alpha_{2}$ and $\lambda \alpha_{\mathrm{b}}$, respectively. When a product is depleted, the sales of the remaining product will also be a Poisson process, however with modified rates $\lambda \alpha_{2}^{\prime}$ or $\lambda \alpha_{1}^{\prime}$.

\subsection{Sales probabilities}

Let $N_{1}, N_{2}, N_{\mathrm{b}}$ denote the numbers of Product 1, Product 2 and the bundle that are sold during the selling horizon which starts with $Q_{1}$ units of Product 1 and $Q_{2}$ units of Product 2. Also let

$P\left(n_{1}, n_{2}, n_{\mathrm{b}}\right)=P\left(N_{1}=n_{1}, N_{2}=n_{2}, N_{\mathrm{b}}=n_{\mathrm{b}}\right)$

be the joint probability function for such sales. ${ }^{1}$ The derivation of $P\left(n_{1}, n_{2}, n_{\mathrm{b}}\right)$ needs a careful consideration. There are four possible realizations for any selling horizon: (i) No stockout in any products, (ii) Stockout only in Product 2, (iii) Stockout only in Product 1, and (iv) Stockout in both products. When there is stockout in both products, one should also keep track of the order of the stockout times since this changes the dynamics of the purchasing behavior of the customers. Next, the calculation of $P\left(n_{1}, n_{2}, n_{\mathrm{b}}\right)$ is illustrated.

Case 1. No stockout in any products: in this case we have $n_{1}+n_{\mathrm{b}}<Q_{1}$ and $n_{2}+n_{\mathrm{b}}<Q_{2}$.

Since both products are available until the end of the season, $N_{1}, N_{2}$ and $N_{\mathrm{b}}$ behave as independent Poisson random variables through the selling season and we have

$P\left(n_{1}, n_{2}, n_{\mathrm{b}}\right)=\frac{\mathrm{e}^{-\lambda \alpha_{1} T}\left(\lambda \alpha_{1} T\right)^{n_{1}}}{n_{1} !} \frac{\mathrm{e}^{-\lambda \alpha_{2} T}\left(\lambda \alpha_{2} T\right)^{n_{2}}}{n_{2} !} \frac{\mathrm{e}^{-\lambda \alpha_{\mathrm{b}} T}\left(\lambda \alpha_{\mathrm{b}} T\right)^{n_{\mathrm{b}}}}{n_{\mathrm{b}} !}$

Case 2. No stockout in Product 1 and stockout in Product 2 .

\footnotetext{
${ }^{1}$ Clearly, $\alpha_{0}(\mathbf{p}), \alpha_{1}(\mathbf{p}), \alpha_{2}(\mathbf{p}), \alpha_{01}^{\prime}(\mathbf{p}), \alpha_{02}^{\prime}(\mathbf{p})$ and $P\left(n_{1}, n_{2}, n_{\mathrm{b}} ; \mathbf{p}\right)$ is a more proper notation for representing purchasing probabilities and the sales probability since all are functions of $\mathbf{p}=\left(p_{1}, p_{2}, p_{\mathrm{b}}\right)$. However, for brevity, we drop the vector $\mathbf{p}$ from the notation except in Sections 2.3.1 and 4 .
}

Suppose now, Product 2 stocks out during the planning horizon but there is at least one unit of Product 1 on hand at the end. This corresponds to having $n_{1}+n_{\mathrm{b}}<Q_{1}$ and $n_{2}+n_{\mathrm{b}}=Q_{2}$.

We first condition on the time $\Xi$, at which Product 2 is depleted. Due to Poisson arrivals, $\Xi$ will have an Erlang distribution, the parameters of which will depend on how the depletion of Product 2 is realized. In particular, the stockout can be experienced either by an individual purchase of Product 2, or by a bundle purchase. Each of these realizations induce different dynamics to the system. Suppose a stockout occurs in Product 2 at the time instance $\xi$ and let $N_{11}(\xi)$ be the number of Product 1 that is sold in the interval $(0, \xi]$. If the last purchase that depletes the inventory of Product 2 is a single purchase, then $\Xi$ will have an Erlang distribution with shape and scale parameters $n_{2}$ and $\alpha_{2} \lambda$, respectively. This implies that $n_{\mathrm{b}}$ bundle purchases have occurred in $(0, \xi]$. If the last purchase however, is a bundle, then $\Xi$ will have an Erlang distribution with shape and scale parameters $n_{\mathrm{b}}$ and $\alpha_{\mathrm{b}} \lambda$, respectively. This will then imply that $n_{2}$ individual Product 2 purchases have occurred in $(0, \xi]$. In either case, if $N_{11}(\xi)=n_{11}$, this corresponds to $n_{11}$ Product 1 purchases in $(0, \xi]$ and $n_{1}-n_{11}$ Product 1 purchases in $(\xi, T]$. Let $g_{\beta, \theta}($.$) denote$ the probability density function of an Erlang variable with shape and scale parameters $\beta$ and $\theta$. Also let $I(a \geqslant b)$ be an indicator function which equals 1 if $a$ is larger than or equal to $b, 0$ otherwise.

Then, conditioning on $\Xi$ and how the stockout of Product 2 is realized, we have

$$
\begin{aligned}
P\left(n_{1}, n_{2}, n_{\mathrm{b}}\right)= & I\left(n_{2} \geqslant 1\right) \int_{0}^{T} A(\xi) g_{n_{2}, \alpha_{2} \lambda}(\xi) \mathrm{d} \xi+I\left(n_{\mathrm{b}} \geqslant 1\right) \\
& \times \int_{0}^{T} B(\xi) g_{n_{\mathrm{b}}, \alpha_{\mathrm{b}} \lambda}(\xi) \mathrm{d} \xi,
\end{aligned}
$$

where

$$
\begin{aligned}
A(\xi) \equiv & \sum_{n_{11}=0}^{n_{1}} \frac{\mathrm{e}^{-\lambda \alpha_{1} \xi}\left(\lambda \alpha_{1} \xi\right)^{n_{11}}}{n_{11} !} \frac{\mathrm{e}^{-\lambda \alpha_{1}^{\prime}(T-\xi)}\left(\lambda \alpha_{1}^{\prime}(T-\xi)\right)^{n_{1}-n_{11}}}{\left(n_{1}-n_{11}\right) !} \\
& \times \frac{\mathrm{e}^{-\lambda \alpha_{\mathrm{b}} \xi}\left(\lambda \alpha_{\mathrm{b}} \xi\right)^{n_{\mathrm{b}}}}{n_{\mathrm{b}} !}
\end{aligned}
$$

and

$$
\begin{aligned}
B(\xi) \equiv & \sum_{n_{11}=0}^{n_{1}} \frac{\mathrm{e}^{-\lambda \alpha_{1} \xi}\left(\lambda \alpha_{1} \xi\right)^{n_{11}}}{n_{11} !} \frac{\mathrm{e}^{-\lambda \alpha_{1}^{\prime}(T-\xi)}\left(\lambda \alpha_{1}^{\prime}(T-\xi)\right)^{n_{1}-n_{11}}}{\left(n_{1}-n_{11}\right) !} \\
& \times \frac{\mathrm{e}^{-\lambda \alpha_{2} \xi}\left(\lambda \alpha_{2} \xi\right)^{n_{2}}}{n_{2} !}
\end{aligned}
$$

Case 3. No stockout in Product 2 and stockout in Product 1.

The purchase probabilities for this case are obtained in a manner similar to the previous case. For $n_{1}+n_{\mathrm{b}}=Q_{1}$ and $n_{2}+n_{\mathrm{b}}<Q_{2}$, we have 


$$
\begin{aligned}
P\left(n_{1}, n_{2}, n_{\mathrm{b}}\right)= & I\left(n_{1} \geqslant 1\right) \int_{0}^{T} A(\xi) g_{n_{1}, \alpha_{1} \lambda}(\xi) \mathrm{d} \xi+I\left(n_{\mathrm{b}} \geqslant 1\right) \\
& \times \int_{0}^{T} B(\xi) g_{n_{\mathrm{b}}, \alpha_{\mathrm{b}} \lambda}(\xi) \mathrm{d} \xi,
\end{aligned}
$$

where

$$
\begin{aligned}
& A(\xi) \equiv \sum_{n_{21}=0}^{n_{2}} \frac{\mathrm{e}^{-\lambda \alpha_{2} \xi}\left(\lambda \alpha_{2} \xi\right)^{n_{21}}}{n_{21} !} \frac{\mathrm{e}^{-\lambda \alpha_{2}^{\prime}(T-\xi)}\left(\lambda \alpha_{2}^{\prime}(T-\xi)\right)^{n_{2}-n_{21}}}{\left(n_{2}-n_{21}\right) !} \frac{\mathrm{e}^{-\lambda \alpha_{\mathrm{b}} \xi}\left(\lambda \alpha_{\mathrm{b}} \xi\right)^{n_{\mathrm{b}}}}{n_{\mathrm{b}} !} \\
& B(\xi) \equiv \sum_{n_{21}=0}^{n_{2}} \frac{\mathrm{e}^{-\lambda \alpha_{2} \xi}\left(\lambda \alpha_{2} \xi\right)^{n_{21}}}{n_{21} !} \frac{\mathrm{e}^{-\lambda \alpha_{2}^{\prime}(T-\xi)}\left(\lambda \alpha_{2}^{\prime}(T-\xi)\right)^{n_{2}-n_{21}}}{\left(n_{2}-n_{21}\right) !} \frac{\mathrm{e}^{-\lambda \alpha_{1} \xi}\left(\lambda \alpha_{1} \xi\right)^{n_{1}}}{n_{1} !} .
\end{aligned}
$$

Case 4. Stockout in both products.

Suppose now that both products are depleted during the planning horizon which corresponds to the case $n_{1}+n_{\mathrm{b}}=$ $Q_{1}$ and $n_{2}+n_{\mathrm{b}}=Q_{2}$. We first observe that stockout in both products can occur by three different realizations: Product 1 or Product 2 depletes first, or both can deplete simultaneously by a bundle purchase. Corresponding to each of these realizations we define separate sales probabilities $P_{A}\left(n_{1}, n_{2}, n_{\mathrm{b}}\right)$ (Product 1 depletes first), $P_{B}\left(n_{1}, n_{2}, n_{\mathrm{b}}\right)$ (Product 2 depletes first) and $P_{C}\left(n_{1}, n_{2}, n_{\mathrm{b}}\right)$ (both products deplete simultaneously) such that

$P\left(n_{1}, n_{2}, n_{\mathrm{b}}\right)=P_{A}\left(n_{1}, n_{2}, n_{\mathrm{b}}\right)+P_{B}\left(n_{1}, n_{2}, n_{\mathrm{b}}\right)+P_{C}\left(n_{1}, n_{2}, n_{\mathrm{b}}\right)$.

We now derive these sales probabilities.

First we derive $P_{A}\left(n_{1}, n_{2}, n_{\mathrm{b}}\right)$. Suppose Product 1 depletes first at time $\Xi_{1}=\xi_{1}$ and let $N_{21}^{\prime}\left(\xi_{1}\right)$ be the number of Product 2 that is sold in $\left(0, \xi_{1}\right]$. Similar to the previous case, the last purchase that causes the stockout of Product 1 can be either a single or a bundle purchase. If it is a single purchase, $\Xi_{1}$ has an Erlang distribution with parameters $n_{1}$ and $\alpha_{1} \lambda$ and there are $n_{\mathrm{b}}$ bundle purchases in $\left(0, \xi_{1}\right]$. If it is a bundle, $\Xi_{1}$ has an Erlang distribution with parameters $n_{\mathrm{b}}$ and $\alpha_{\mathrm{b}} \lambda$ and there are $n_{1}$ Product 1 purchases in $\left(0, \xi_{1}\right]$. In either case, $N_{21}^{\prime}\left(\xi_{1}\right)=n_{21}^{\prime}$ implies that there are $n_{21}^{\prime}$ Product 2 purchases in $\left(0, \xi_{1}\right]$. The maximum value that $n_{21}^{\prime}$ can take is $n_{2}-1$, since we have to ensure that Product 2 has not depleted before Product 1 . Also, in order that Product 2 is depleted by the end of the selling season, we must have at least $n_{2}-n_{21}$ Product 2 purchases in $\left(\xi_{1}, T\right]$. Letting as before

$$
\begin{aligned}
A\left(\xi_{1}\right) \equiv & \sum_{n_{21}^{\prime}=0}^{\max \left(n_{2}-1,0\right)} \sum_{k=n_{2}-n_{21}^{\prime}}^{\infty} \frac{\mathrm{e}^{-\lambda \alpha_{2} \xi_{1}}\left(\lambda \alpha_{2} \xi_{1}\right)^{n_{21}^{\prime}}}{n_{21}^{\prime} !} \\
& \times \frac{\mathrm{e}^{-\lambda \alpha_{2}^{\prime}\left(T-\xi_{1}\right)}\left(\lambda \alpha_{2}^{\prime}\left(T-\xi_{1}\right)\right)^{k}}{k !} \frac{\mathrm{e}^{-\lambda \alpha_{\mathrm{b}} \xi_{1}}\left(\lambda \alpha_{\mathrm{b}} \xi_{1}\right)^{n_{\mathrm{b}}}}{n_{\mathrm{b}} !}
\end{aligned}
$$

and

$$
\begin{aligned}
B\left(\xi_{1}\right) \equiv & \sum_{n_{21}^{\prime}=0}^{\max \left(n_{2}-1,0\right)} \sum_{k=n_{2}-n_{21}^{\prime}}^{\infty} \frac{\mathrm{e}^{-\lambda \alpha_{2} \xi_{1}}\left(\lambda \alpha_{2} \xi_{1}\right)^{n_{21}^{\prime}}}{n_{21}^{\prime} !} \\
& \times \frac{\mathrm{e}^{-\lambda \alpha_{2}^{\prime}\left(T-\xi_{1}\right)}\left(\lambda \alpha_{2}^{\prime}\left(T-\xi_{1}\right)\right)^{k}}{k !} \frac{\mathrm{e}^{-\lambda \alpha_{1} \xi_{1}}\left(\lambda \alpha_{1} \xi_{1}\right)^{n_{1}}}{n_{1} !},
\end{aligned}
$$

we have

$$
\begin{aligned}
P_{A}\left(n_{1}, n_{2}, n_{\mathrm{b}}\right)= & I\left(n_{1} \geqslant 1\right) \int_{0}^{T} A\left(\xi_{1}\right) g_{n_{1}, \alpha_{1} \lambda}\left(\xi_{1}\right) d \xi_{1}+I\left(n_{\mathrm{b}} \geqslant 1\right) \\
& \times \int_{0}^{T} B\left(\xi_{1}\right) g_{n_{\mathrm{b}}, \alpha_{\mathrm{b}} \lambda}\left(\xi_{1}\right) \mathrm{d} \xi_{1} .
\end{aligned}
$$

The derivation of $P_{B}\left(n_{1}, n_{2}, n_{\mathrm{b}}\right)$ is the same as the derivation of $P_{A}\left(n_{1}, n_{2}, n_{\mathrm{b}}\right)$, except that we now assume Product 2 depletes first.

In order to derive $P_{C}\left(n_{1}, n_{2}, n_{\mathrm{b}}\right)$, let $\Xi_{12}=\xi_{12}$ be the time that both products deplete simultaneously by a bundle purchase. Then $\Xi_{12}$ has an Erlang distribution with parameters $n_{\mathrm{b}}, \alpha_{\mathrm{b}} \lambda$, and $n_{1}$ units of Product 1 and $n_{2}$ units of Product 2 are sold in $\left(0, \xi_{12}\right]$. Thus, we have

$$
\begin{aligned}
P_{C}\left(n_{1}, n_{2}, n_{\mathrm{b}}\right)= & \int_{0}^{T} \frac{\mathrm{e}^{-\lambda \alpha_{1} \xi_{12}}\left(\lambda \alpha_{1} \xi_{12}\right)^{n_{1}}}{n_{1} !} \\
& \times \frac{\mathrm{e}^{-\lambda \alpha_{2} \xi_{12}}\left(\lambda \alpha_{2} \xi_{12}\right)^{n_{2}}}{n_{2} !} g_{n_{\mathrm{b}}, \alpha_{\mathrm{b}} \lambda}\left(\xi_{12}\right) \mathrm{d} \xi_{12} .
\end{aligned}
$$

\subsubsection{Optimization problem}

Having provided the sales probabilities for different realizations, we can now state the optimization problem. For given initial stock levels $Q_{1}$ and $Q_{2}$, the problem is to find the individual product prices and the bundle price, i.e., $\mathbf{p}=\left(p_{1}, p_{2}, p_{\mathrm{b}}\right)$, so that the expected revenue is maximized. Thus, the problem for the mixed bundling case can be expressed as

$$
\begin{aligned}
& \max _{\mathbf{p}} \sum_{n_{1}, n_{2}, n_{\mathrm{b}}}\left(p_{1} n_{1}+p_{2} n_{2}+p_{\mathrm{b}} n_{\mathrm{b}}\right) P\left(n_{1}, n_{2}, n_{\mathrm{b}} ; \mathbf{p}\right) \\
& \text { s.t. } p_{1}+p_{2} \geqslant p_{\mathrm{b}} .
\end{aligned}
$$

The problem is a non-linear program with a single constraint on prices.

\subsection{Unbundling and pure bundling strategies}

The analysis for the unbundling and pure bundling strategies are carried out similarly, except with modified purchasing probabilities. In the unbundling case an arriving customer can buy nothing, buy Product 1 or Product 2 or both at a price $p_{1}+p_{2}$ with the following purchasing probabilities:

$$
\begin{aligned}
& \alpha_{0}=P\left(R_{1} \leqslant p_{1}, R_{2} \leqslant p_{2}\right), \\
& \alpha_{1}=P\left(R_{1} \geqslant p_{1}, R_{2} \leqslant p_{2}\right), \\
& \alpha_{2}=P\left(R_{1} \leqslant p_{1}, R_{2} \geqslant p_{2}\right), \\
& \alpha_{\mathrm{b}}=P\left(R_{1} \geqslant p_{1}, R_{2} \geqslant p_{2}\right) .
\end{aligned}
$$

Pure bundling simply refers to the case with a single product, the bundle. The customer either buys the product with probability $\alpha_{\mathrm{b}}=P\left(R_{1}+R_{2} \geqslant p_{\mathrm{b}}\right)$, or leaves without a purchase with probability $\alpha_{0}=1-\alpha_{\mathrm{b}}$. For comparison purposes, we have included this case in our numerical study, however such a comparison is somewhat restricted since it is reasonable to make comparisons only when $Q_{1}=Q_{2}$. 


\subsection{Superadditivity and subadditivity of reservation prices}

The analysis so far assumes that the consumer's reservation price for the bundle is equal to the sum of her reservation prices for the individual products, i.e., $R_{\mathrm{b}}=R_{1}+R_{2}$. When the two products are complements or substitutes, the assumption of strict additivity does not hold. Following the approach in Venkatesh and Kamakura (2003), we define $\theta$ to measure the degree of contingency (the degree of complementarity or substitutability) given by

$\theta=\frac{R_{\mathrm{b}}-\left(R_{1}+R_{2}\right)}{R_{1}+R_{2}}$.

As noted in Venkatesh and Kamakura (2003), "correlation in reservation prices and the degree of contingency are two distinct notions. While the degree of contingency parameter $\theta$ captures perceived value enhancement or reduction within each consumer, the correlation in reservation prices for two products shows how stand-alone reservation prices relate to each other across consumers".

We note that the characterization of the degree of contingency given in (1) is rather restrictive and forces the reservation price of the bundle to be an exact linear combination of the reservation prices. More general characterizations are possible including defining a trivariate distribution for the reservation prices for Product 1, Product 2 and bundle as is done in Jedidi et al. (2003).

With the characterization in (1), the purchase probabilities can be calculated in a way similar to the one in Section 2.2. The purchase probabilities when there is no stockout can be calculated by observing $R_{\mathrm{b}}=(1+\theta)\left(R_{1}+R_{2}\right)$. The no purchase probability is given by

$$
\begin{aligned}
\alpha_{0} & =P\left(R_{1}<p_{1}, R_{2}<p_{2}, R_{\mathrm{b}}<p_{\mathrm{b}}\right) \\
& =P\left(R_{1}<p_{1}, R_{2}<p_{2},(1+\theta)\left(R_{1}+R_{2}\right)<p_{\mathrm{b}}\right) \\
& =P\left(R_{1}<p_{1}, R_{2}<\min \left\{p_{2},\left(p_{\mathrm{b}}-(1+\theta) R_{1}\right) /(1+\theta)\right\}\right) \\
& =\int_{-\infty}^{p_{1}} \int_{-\infty}^{a_{1}} f_{R_{1}, R_{2}}\left(r_{1}, r_{2}\right) \mathrm{d} r_{2} \mathrm{~d} r_{1}
\end{aligned}
$$

where $a_{1}=\min \left\{p_{2},\left(p_{\mathrm{b}}-(1+\theta) r_{1}\right) /(1+\theta)\right\}$.

The purchase probability of the first product is given by

$$
\begin{aligned}
\alpha_{1}= & P\left(R_{1}>p_{1}, R_{1}-p_{1}>R_{2}-p_{2}, R_{1}-p_{1}>R_{\mathrm{b}}-p_{\mathrm{b}}\right) \\
= & P\left(R_{1}>p_{1}, R_{1}-p_{1}>R_{2}-p_{2},\right. \\
& \left.R_{1}-p_{1}>(1+\theta)\left(R_{1}+R_{2}\right)-p_{\mathrm{b}}\right)=P\left(R_{1}>p_{1},\right. \\
& \left.R_{2}<\min \left\{R_{1}-p_{1}+p_{2},\left(p_{\mathrm{b}}-p_{1}-\theta R_{1}\right) /(1+\theta)\right\}\right) \\
= & \int_{p_{1}}^{\infty} \int_{-\infty}^{a_{2}} f_{R_{1}, R_{2}}\left(r_{1}, r_{2}\right) \mathrm{d} r_{2} \mathrm{~d} r_{1},
\end{aligned}
$$

where $a_{2}=\min \left\{r_{1}-p_{1}+p_{2},\left(p_{\mathrm{b}}-p_{1}-\theta r_{1}\right) /(1+\theta)\right\}$. The purchase probability of the second product is obtained similarly as

$\alpha_{2}=\int_{p_{2}}^{\infty} \int_{-\infty}^{a_{3}} f_{R_{1}, R_{2}}\left(r_{1}, r_{2}\right) \mathrm{d} r_{1} \mathrm{~d} r_{2}$ where $a_{3}=\min \left\{r_{2}-p_{2}+p_{1},\left(p_{\mathrm{b}}-p_{2}-\theta r_{2}\right) /(1+\theta)\right\}$. Finally, the purchase probability of the bundle can be derived as

$\alpha_{\mathrm{b}}=1-\alpha_{0}-\alpha_{1}-\alpha_{2}$.

The purchase probabilities when there is a stockout are the same as those given in Section 2.2.

\subsection{An example}

In a recent study, Jedidi et al. (2003) develop a model for capturing heterogeneity in the joint distribution of the reservation prices of products and provide three examples for which they conduct experiments to estimate reservation price distributions. We present below an application of our methodology for two of their examples: a combination of a video camera (VC) and a video cassette player/recorder (VP) and a combination of a microwave oven (MO) and television (TV). Jedidi et al. provide the estimates given in Table 1 for the parameters of the reservation price distributions, assuming normality. ${ }^{2}$

Jedidi et al. use a profit maximization approach to determine the optimal product and bundle prices assuming that the products can be acquired upon the request of the customer (or unsold inventory can be returned at the marginal cost). Using numerical methods, the profit maximizing prices $\left(p_{1}, p_{2}, p_{\mathrm{b}}\right)=(520,256,670)$ for the VC-VP pair and $\left(p_{1}, p_{2}, p_{\mathrm{b}}\right)=(235,314,510)$ for the MO-TV pair are obtained.

In contrast to the work of Jedidi et al., we assume that the inventory decisions are already made by the retailer (which is valid for significantly many industries) and the retailer maximizes its revenues over a finite selling season without any further replenishment opportunities. Using our model, which also allows for substitution in stockout times, with $\lambda=20$ and $T=1$, the optimal product prices and bundle prices are computed for a variety of starting inventory levels for the reservation price distribution parameters given in Table 1. The results are reported in Table 2.

For the VC-VP pair, the products are partial substitutes $(\theta=-0.13)$, and the reservation prices are strongly positively correlated $(\rho=0.89)$. As seen from Table 2 , when the starting inventory levels are low, the retailer does not utilize bundling since bundling is rather ineffective due to high correlation (this will be further discussed in our numerical study in the next section). When the starting inventories are equal, the retailer prices the products and the bundle so that more demand is shifted to the more expensive VC. Finally observe that as the starting inventories are increased, the retailer uses more bundling and the expected revenue increases.

\footnotetext{
${ }^{2}$ As discussed in Section 2.5, we use the characterization in (1) for the degree of contingency rather than the trivariate reservation price distribution modeling in Jedidi et al.
} 
Table 1

The data for the example

\begin{tabular}{lrrrr}
\hline Product group & VC & \multicolumn{1}{c}{ VP } & MO & \multicolumn{1}{c}{ TV } \\
\hline Average reservation price $\left(\mu_{i}\right)$ & 561.81 & 231.21 & 157.69 & 264.40 \\
Standard deviation $\left(\sigma_{i}\right)$ & 89.00 & 62.89 & 67.34 & 74.73 \\
Correlation coefficient $(\rho)$ & 0.89 & & 0.51 & \\
Degree of contingency $(\theta)$ & -0.13 & & 0 & \\
\hline
\end{tabular}

For the MO-TV pair, the products are neither substitutes nor complements $(\theta=0)$, and the reservation prices are moderately positively correlated $(\rho=0.51)$. We note from Table 2 that as the starting inventory levels increase, the prices decrease and the revenue increases. If there is an asymmetry in the inventory levels of the products, the prices change inversely with the number of available products. For this pair, bundling is an effective option and we note a sharper decrease in bundle prices as inventory levels increase.

Although the profit maximization approach of Jedidi et al. and the approach proposed in this study are not directly comparable, we report in columns 7 and 13 of Table 2 the expected revenues if the retailer charges the prices $\left(p_{1}, p_{2}, p_{\mathrm{b}}\right)=(520,256,670)$ for the VC-VP pair and $\left(p_{1}, p_{2}, p_{\mathrm{b}}\right)=(235,314,510)$ for the MO-TV pair even though the starting inventory levels are fixed as given in the first two columns and no further replenishments are possible. Columns 8 and 14 report the percentage revenue gaps. This comparison emphasizes the sub-optimality that would result from using the optimal prices from a model that does not take the inventory availability explicitly into account. Note that the percentage revenue gap does not depend on the starting inventory levels in any particular way. In other words, there is no general condition under which maximizing profit without inventory considerations is guaranteed to give a good solution for the problem we consider. The solution to the profit maximization problem depends on the marginal costs, while the solution to the problem we consider depends on the starting inventory levels, the arrival rate and the length of the horizon. Therefore, if the purchasing decisions are made a priori and the retailer needs to sell a fixed amount of stock over a selling season, she needs to consider the starting inventory levels and the intensity of the store arrivals to decide whether she should apply a bundling strategy and if so, what prices. We should note that there are some industries (e.g., high technology) where a profit maximization approach can be used to optimize prices when the company is still using replenishments to meet future demand. But once the company starts to operate in a liquidation mode (e.g., as in the sales of soon-to-be-obsolete inventories), the company should adopt distinctly different bundling and pricing strategies.

\section{Numerical results}

We now present the results of our numerical study to illustrate the impact of various factors on pricing decisions in the presence of bundling. Our primary focus is the mixed bundling strategy and the factors that we consider are the correlation between the reservation prices, the starting inventory levels and the degree of contingency. We also investigate the conditions under which a mixed bundling strategy provides the largest profit gains against pure bundling and unbundling strategies. In this paper, we report the most significant findings of the numerical study. For a more detailed exposition of the numerical results, please see Bulut et al. (2006).

In our numerical study, we first assume that customer reservation price pairs follow a bivariate normal distribution and investigate the impact of several factors on the revenue with this assumption. The normal distribution is by far the most extensively used one in bundling studies. According to Schmalensee (1984), the Gaussian family is a plausible choice to describe the distribution of customer preferences in a population of buyers. The bivariate normal distribution has a small number of easily interpreted parameters and, due to the additive property, the distribution of the bundle is also normal. One difficulty working with the normal distribution is that it allows for negative values. As Salinger (1995) also argues, as long as an undesirable product of a bundle can be disposed of freely, the assumption of negative valuations is not warranted. Therefore, we select appropriate parameters for the normal distributions in our numerical study to ensure non-negative valuations.

Despite the advantages of normal distributions mentioned above, the symmetry property may not always be realistic in practice for reservation prices, since we would expect less probability for higher prices. To investigate the impact of skewness, in the last part of our numerical

Table 2

Optimal prices for the proposed model

\begin{tabular}{|c|c|c|c|c|c|c|c|c|c|c|c|c|c|}
\hline \multirow[t]{2}{*}{$Q_{1}$} & \multirow[t]{2}{*}{$Q_{2}$} & \multicolumn{6}{|c|}{ VC-VP } & \multicolumn{6}{|c|}{ MO-TV } \\
\hline & & $p_{1}^{*}$ & $p_{2}^{*}$ & $p_{\mathrm{b}}^{*}$ & $E(R)$ & $E_{U}(R)$ & Gap $(\%)$ & $p_{1}^{*}$ & $p_{2}^{*}$ & $p_{\mathrm{b}}^{*}$ & $E(R)$ & $E_{U}(R)$ & Gap $(\%)$ \\
\hline 3 & 3 & 591 & 255 & 816 & 2436 & 2172 & 10.84 & 211 & 317 & 511 & 1469 & 1440 & 1.97 \\
\hline 10 & 10 & 522 & 217 & 658 & 6399 & 6201 & 3.09 & 181 & 275 & 409 & 3769 & 2663 & 29.34 \\
\hline 20 & 20 & 468 & 209 & 566 & 9231 & 7982 & 13.53 & 179 & 242 & 339 & 5044 & 2689 & 46.69 \\
\hline 10 & 20 & 533 & 188 & 621 & 6982 & 6235 & 10.70 & 225 & 221 & 369 & 4621 & 2688 & 41.83 \\
\hline 20 & 10 & 466 & 235 & 591 & 8839 & 7964 & 9.90 & 142 & 300 & 382 & 4119 & 2663 & 35.35 \\
\hline
\end{tabular}


section we considered a bivariate gamma density for reservation prices over a small experimental set.

\subsection{Joint optimization of $p_{1}, p_{2}$ and $p_{\mathrm{b}}$}

We first consider the case where the retailer jointly optimizes the prices of the individual products and the bundle. Throughout the numerical study, we consider a base case to benchmark against different cases. In this base case, the reservation prices for both products are identically distributed with $\mu_{1}=\mu_{2}=15$ and $\sigma_{1}=\sigma_{2}=2$. The degree of contingency $\theta$ is set to 0 . Initial inventories are also identical at $Q_{1}=Q_{2}=10$. We assume $T=1$ and the customer arrival rate to be equal to the total number of individual products available, i.e., $\lambda=20$. The optimal value of the bundle price and product prices are searched over a fixed set in which prices are taken with 0.25 increments. The results for the base case are presented in Table 3. The first column stands for the correlation coefficient, the second column shows the optimal prices and the third column stands for the difference $\left(p_{1}^{*}+p_{2}^{*}\right)-p_{\mathrm{b}}^{*}$. The fourth column represents the optimal expected revenue; the fifth and the sixth columns represent the expected sales of the individual products and the bundle; the seventh and the eighth columns represent the purchase probabilities (when both products are available).

Table 3 shows the significant impact of the correlation coefficient on the optimal prices and expected revenues. We first observe that the optimal prices for the individual products and the bundle, and the optimal revenues decrease as the correlation coefficient increases. Bundling is most effective when the reservation prices are negatively correlated as the reservation price distribution of the bun- dle has the smallest variance in this case. An extreme case is $\rho=-0.9$, when the bundle reservation price's variability is very small and the retailer choose to sell only bundles. When $\rho=-0.5$, the retailer is able to attract a significant number of bundle customers without having to offer a deep discount on the bundle price. High bundle prices also allow the retailer to keep the prices and the demand high for the individual products. When the reservation prices are positively correlated, the retailer has to offer sharper discounts for the bundle. This reduces the revenue (per unit sold) for the bundle and also reduces the demand for the individual products despite low prices. The observation that bundling is particularly beneficial with negatively correlated reservation prices is also made in earlier research in the marketing and economics literature; namely in Adams and Yellen (1976), Schmalensee (1984), Long (1984) and Salinger (1995). (However, as mentioned in Section 1, these papers do not consider inventory availability and do not explicitly model the customer arrival process over a selling horizon).

Next, we consider the impact of initial inventory levels on the expected revenues and optimal prices. We consider two other quantity combinations. Table 4 has results for the case of limited inventories, $\left(Q_{1}=Q_{2}=5\right)$ and for the case of excess inventories, $\left(Q_{1}=Q_{2}=15\right)$. We first observe that when the initial inventories are higher, the retailer's revenues are also higher, which is expected. The optimal bundle price decreases as the starting inventory levels increase. When the inventories are limited $\left(Q_{1}=Q_{2}=5\right)$, the retailer sets all the prices high, and sells a significant number of products individually (especially when the correlation is negative). When the retailer has excess inventories $\left(Q_{1}=Q_{2}=15\right)$, the retailer sets the individual product prices high and sells only through bundling.

Table 3

Joint optimization - base case

\begin{tabular}{lllllll}
\hline$\rho$ & $\left(p_{1}^{*}=p_{2}^{*}, p_{\mathrm{b}}^{*}\right)$ & $d$ & $E(R)$ & $E\left(n_{1}\right)=E\left(n_{2}\right)$ & $E\left(n_{\mathrm{b}}\right)$ & $\alpha_{1}=\alpha_{2}$ \\
\hline-0.9 & $(25.75,29.25)$ & 22.25 & 290.10 & 0.00 & 9.92 & 0.00 \\
-0.5 & $(16.00,28.75)$ & 3.25 & 283.57 & 1.48 & 8.21 & 0.08 \\
0 & $(15.50,28.50)$ & 2.50 & 279.64 & 1.23 & 8.47 & 0.06 \\
0.5 & $(15.25,28.50)$ & 2.00 & 276.84 & 0.72 & 8.94 & 0.03 \\
0.9 & $(14.75,28.50)$ & 1.00 & 274.83 & 0.27 & 9.36 & 0.63 \\
\hline
\end{tabular}

Table 4

Joint optimization - impact of starting inventory $\left(\mu_{1}=\mu_{2}=15, \sigma_{1}=\sigma_{2}=2\right)$

\begin{tabular}{|c|c|c|c|c|c|c|c|c|}
\hline$Q_{1}=Q_{2}$ & $\rho$ & $\left(p_{1}^{*}=p_{2}^{*}, p_{\mathrm{b}}^{*}\right)$ & $d$ & $E(R)$ & $E\left(n_{1}\right)=E\left(n_{2}\right)$ & $E\left(n_{\mathrm{b}}\right)$ & $\alpha_{1}=\alpha_{2}$ & $\alpha_{\mathrm{b}}$ \\
\hline 5 & -0.9 & $(16.00,30.00)$ & 2.00 & 152.08 & 2.78 & 2.11 & 0.25 & 0.25 \\
\hline 5 & -0.5 & $(16.00,30.25)$ & 1.75 & 151.35 & 2.29 & 2.58 & 0.18 & 0.28 \\
\hline 5 & 0 & $(15.75,30.50)$ & 1.00 & 150.93 & 2.16 & 2.72 & 0.16 & 0.28 \\
\hline 5 & 0.5 & $(15.75,30.75)$ & 0.75 & 150.58 & 1.52 & 3.33 & 0.10 & 0.32 \\
\hline 5 & 0.9 & $(15.50,30.75)$ & 0.25 & 150.31 & 0.84 & 4.04 & 0.02 & 0.40 \\
\hline 15 & -0.9 & $(25.75,28.75)$ & 22.75 & 417.44 & 0.00 & 14.52 & 0.00 & 0.92 \\
\hline 15 & -0.5 & $(25.75,27.75)$ & 23.75 & 397.02 & 0.00 & 14.31 & 0.00 & 0.87 \\
\hline 15 & 0 & $(25.75,27.25)$ & 24.25 & 384.54 & 0.00 & 14.11 & 0.00 & 0.83 \\
\hline 15 & 0.5 & $(25.75,27.00)$ & 24.50 & 376.06 & 0.00 & 13.93 & 0.00 & 0.81 \\
\hline 15 & 0.9 & $(25.75,26.75)$ & 24.75 & 370.83 & 0.00 & 13.86 & 0.00 & 0.80 \\
\hline
\end{tabular}




\subsection{Fixed $p_{1}$ and $p_{2}$}

We now consider the case where the individual product prices are externally set and the retailer is optimizing only the bundle price. As in Section 3.1 we use the values $Q_{1}=Q_{2}=10, \mu_{1}=\mu_{2}=15, \sigma_{1}=\sigma_{2}=2, \lambda=20$ and $\theta=0$. Fig. 1 shows how the expected revenue changes with the bundle price, for three different correlation values $(\rho=-0.9,0.0,0.9)$ and when $p_{1}=p_{2}=15$. For all three correlation values, expected revenue appears to be concave in the bundle price. For all bundle prices, highest expected revenue is obtained for the negative correlation case, followed by the no correlation and positive correlation cases. The differences are small when the bundle price is very low (i.e., most customers purchase the bundle) and the differences disappear when the bundle price is very high (i.e., none of the customers purchase the bundle). The impact of the correlation on expected revenues is highest when the retailer charges a bundle price around the optimal. In Table 5, we show the results

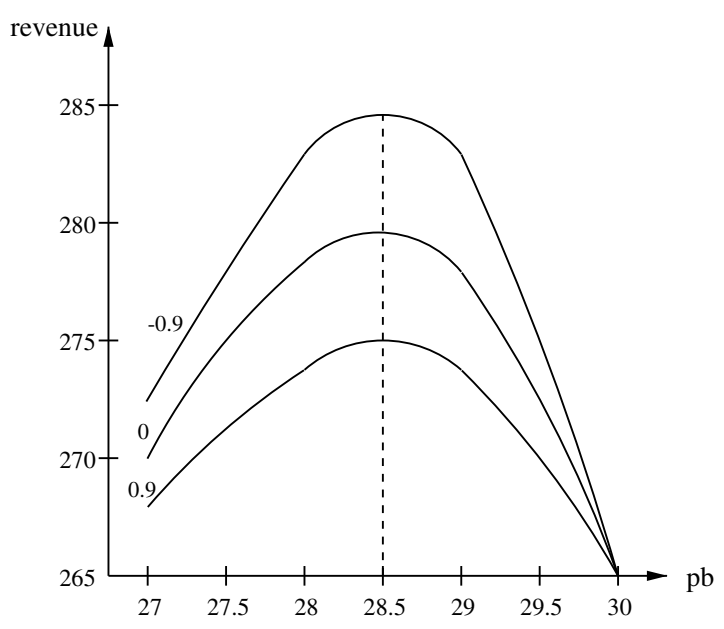

Fig. 1. Revenue vs. bundle price, $p_{1}=p_{2}=15$. of the same problem when $p_{1}=p_{2}$ is in set $\{14,15,16\}$ and report the optimal bundle price (in column 3) and the optimal expected revenues (in column 9). In addition, column 4 reports the probability of no purchase when both products are available, and column 10 reports the probability of purchase when only one of the products is available. The way the correlation coefficient impacts the optimal bundle price and the optimal expected revenues depends on the individual product prices. When the individual product prices are high (i.e., $p_{1}=p_{2}=16$ ), most of the customers would not make a purchase, if the bundle option is not offered (Note that the probability of no purchase $\alpha_{0}$ is high). In this case, the retailer offers a bundle price that will trigger non-buyers to buy the bundle. This can be done best if the variance of the bundle reservation price is smallest. This way, the retailer can improve sales by small reductions in the bundle price. As the correlation coefficient decreases, the variance of the bundle reservation price decreases. Hence, the optimal expected revenue and the optimal bundle price are decreasing functions of the correlation coefficient for high individual product prices. When the individual product prices are low (i.e., $\left.p_{1}=p_{2}=14\right)$, most customers would buy one of the products even if the bundle option is not offered (Note that the probability of no purchase $\alpha_{0}$ is low). In this case, the retailer would like to move some of these customers from buying individual products to buying the bundle. When the customers that already intend to buy one of the products value the other product highly as well (positive correlation), the retailer does not have to offer a deep discount on the bundle price to attract these customers. Hence, the optimal bundle price is an increasing function of the correlation coefficient for low individual product prices. When the individual product prices are moderate (i.e., $p_{1}=p_{2}=15$ ), both of the effects above cancel each other and we do not observe any impact of the correlation coefficient on the bundle price.

Table 5

Fixed $p_{1}$ and $p_{2}\left(\mu_{1}=\mu_{2}=15, \sigma_{1}=\sigma_{2}=2, Q_{1}=Q_{2}=10\right)$

\begin{tabular}{|c|c|c|c|c|c|c|c|c|c|}
\hline$\rho$ & $p_{1}=p_{2}$ & $p_{\mathrm{b}}^{*}$ & $\alpha_{0}$ & $\alpha_{1}=\alpha_{2}$ & $\alpha_{\mathrm{b}}$ & $E\left(n_{1}\right)=E\left(n_{2}\right)$ & $E\left(n_{\mathrm{b}}\right)$ & $E(R)$ & $\alpha_{1}^{\prime}=\alpha_{2}^{\prime}$ \\
\hline-0.9 & 14 & 27.75 & 0.00 & 0.27 & 0.47 & 4.15 & 5.68 & 273.78 & 0.69 \\
\hline-0.5 & 14 & 27.75 & 0.04 & 0.24 & 0.49 & 3.80 & 6.02 & 273.43 & 0.69 \\
\hline 0 & 14 & 28.00 & 0.10 & 0.21 & 0.48 & 3.57 & 6.18 & 273.15 & 0.69 \\
\hline 0.9 & 14 & 28.00 & 0.25 & 0.06 & 0.63 & 1.27 & 8.49 & 273.15 & 0.69 \\
\hline-0.9 & 15 & 28.50 & 0.02 & 0.22 & 0.54 & 3.44 & 6.36 & 284.59 & 0.50 \\
\hline-0.5 & 15 & 28.50 & 0.12 & 0.17 & 0.53 & 2.92 & 6.80 & 281.51 & 0.50 \\
\hline 0.9 & 15 & 28.50 & 0.35 & 0.00 & 0.65 & 0.08 & 9.55 & 274.75 & 0.50 \\
\hline-0.9 & 16 & 29.00 & 0.08 & 0.15 & 0.62 & 2.34 & 7.40 & 289.51 & 0.31 \\
\hline-0.5 & 16 & 28.75 & 0.21 & 0.08 & 0.63 & 1.48 & 8.21 & 283.57 & 0.31 \\
\hline 0 & 16 & 28.75 & 0.30 & 0.04 & 0.62 & 0.82 & 8.81 & 279.50 & 0.31 \\
\hline 0.5 & 16 & 28.50 & 0.33 & 0.01 & 0.66 & 0.15 & 9.53 & 276.43 & 0.31 \\
\hline 0.9 & 16 & 28.50 & 0.35 & 0.00 & 0.65 & 0.00 & 9.64 & 274.68 & 0.31 \\
\hline
\end{tabular}




\subsection{Comparison of the bundling strategies}

We now compare three bundling strategies; mixed bundling, pure bundling and unbundled sales. We analyze the impact of starting inventory levels on the performances of these strategies and explore the conditions under which bundling is most useful. Before we discuss the results, we note that mixed bundling is always (weakly) better than pure bundling and unbundling strategies if there are no costs involved. Any pricing policy in an unbundled sales strategy can be replicated in a mixed bundling strategy by charging a sufficiently high price for the bundle. Likewise, any pricing policy in a pure bundling strategy can be replicated in a mixed bundling strategy by charging sufficiently high prices for the individual products.

First, in Table 6, we study the case where both products have equal starting inventory levels. The percent deviations of expected revenues of the pure and unbundling strategies from mixed bundling strategy are calculated as

$$
\begin{aligned}
& \% \text { deviation }_{i}=\left[\left(E_{\text {mix }}(R)-E_{i}(R)\right) / E_{\text {mix }}(R)\right] \times 100 \\
& i \in\{\text { pure, unbundling }\} .
\end{aligned}
$$

The percentage deviation between mixed bundling and pure bundling strategies decreases when the starting inventory increases. When the retailer has a supply much larger than the (average) demand, he sets significantly lower prices for the bundle to make sure that an arriving customer buys both products. As the retailer sells more bundles and fewer individual products, the revenues obtained from mixed bundling and pure bundling approach each other. In contrast, when the starting inventory levels are high, the performance gap between mixed bundling and unbundling increases. As the retailer has a larger supply, the retailer needs to offer substantial discounts on the individual products in unbundling case, while the discounts on the bundle price are not as deep in mixed bundling strategy.

We observe that if the starting inventory levels are equal, the performances of pure bundling and mixed bundling strategies are quite close, especially when inventory levels are high. However, in most applications, the starting inventory levels will not be equal. Table 7 presents the results where $Q_{2}=10$ and $Q_{1}$ varies. As expected, the mixed bundling strategy clearly outperforms pure bundling strategy for unequal inventory levels.

\subsection{Impact of the degree of contingency}

In Table 8, we study the impact of the degree of contingency on a mixed bundling strategy. The analysis is based on our base case, i.e., $\mu_{1}=\mu_{2}=15, \sigma_{1}=\sigma_{2}=2, \lambda=20$, $T=1$ and $Q_{1}=Q_{2}=10$. As discussed in Section 2.5, $\theta<0$ refers to the case where the products are substitutable, while $\theta>0$ refers to the case where the products are complementary. Clearly, optimal expected revenue is an increasing function of $\theta$ for all correlation values. Also, as $\theta$ increases, the retailer sells more bundles and less individual products, despite the increasing bundle prices in this direction. When $\theta=0.10$, the retailer no longer sells any individual products as the bundle becomes a very attractive option for the customers. We also see that the impact of correlation on expected revenues remains the same for non-zero $\theta$ values. Negative correlation reduces the variance of the bundle reservation price and increases the expected revenues of a mixed bundled strategy.

\subsection{Bivariate gamma reservation price distribution}

So far, we have assumed a bivariate normal distribution for the reservation prices, which is the most commonly used distribution in this context. In order to observe the effect of the shape of the reservation price distribution, we now consider a Morgenstern-type bivariate gamma density for a small experimental set. D'Este (1981) discusses the Morgenstern structure and calculates the moments and correlation coefficient of the resulting distribution which are used for our numerical results.

We consider the case where $\mu_{1}=\mu_{2}=2 ; \sigma_{1}=\sigma_{2}=\sqrt{2}$; $\theta=0$; and $\lambda=20$ with two different sets of initial invento-

Table 7

Comparison of mixed and pure bundling strategies for unequal starting

\begin{tabular}{|c|c|c|c|c|c|c|}
\hline \multirow[t]{2}{*}{$\rho$} & \multicolumn{2}{|c|}{$Q_{1}=5, Q_{2}=10$} & \multicolumn{2}{|c|}{$Q_{1}=10, Q_{2}=10$} & \multicolumn{2}{|c|}{$Q_{1}=20, Q_{2}=10$} \\
\hline & $\begin{array}{l}\text { Mixed } \\
E(R)\end{array}$ & $\begin{array}{l}\text { Pure } \\
\%\end{array}$ & $\begin{array}{l}\text { Mixed } \\
E(R)\end{array}$ & $\begin{array}{l}\text { Pure } \\
\%\end{array}$ & $\begin{array}{l}\text { Mixed } \\
E(R)\end{array}$ & $\begin{array}{l}\text { Pure } \\
\%\end{array}$ \\
\hline-0.9 & 218.76 & 32.02 & 290.10 & 0.42 & 382.77 & 24.21 \\
\hline-0.5 & 216.00 & 31.05 & 283.57 & 0.23 & 367.61 & 23.04 \\
\hline 0 & 214.41 & 30.42 & 279.64 & 0.25 & 358.88 & 22.28 \\
\hline 0.5 & 213.02 & 29.73 & 276.84 & 0.21 & 352.69 & 21.67 \\
\hline 0.9 & 212.24 & 29.27 & 274.33 & 0.05 & 350.11 & 21.54 \\
\hline
\end{tabular}
inventory levels $\left(\mu_{1}=\mu_{2}=15, \sigma_{1}=\sigma_{2}=2\right)$

Table 6

\begin{tabular}{|c|c|c|c|c|c|c|c|c|c|}
\hline \multirow[t]{2}{*}{$\rho$} & \multicolumn{3}{|c|}{$Q_{1}=5, Q_{2}=5$} & \multicolumn{3}{|c|}{$\underline{Q_{1}}=10, Q_{2}=10$} & \multicolumn{3}{|c|}{$Q_{1}=15, Q_{2}=15$} \\
\hline & Mixed $E(R)$ & Pure \% & Unb. $\%$ & Mixed $E(R)$ & Pure \% & Unb. $\%$ & Mixed $E(R)$ & Pure $\%$ & Unb. $\%$ \\
\hline-0.9 & 152.08 & 2.21 & 1.27 & 290.10 & 0.42 & 5.43 & 417.44 & 0.00 & 12.96 \\
\hline-0.5 & 151.35 & 1.73 & 0.79 & 283.57 & 0.23 & 3.26 & 397.02 & 0.00 & 7.43 \\
\hline 0 & 150.93 & 1.16 & 0.52 & 279.64 & 0.25 & 1.90 & 384.54 & 0.00 & 4.06 \\
\hline 0.5 & 150.58 & 0.60 & 0.29 & 276.84 & 0.21 & 0.90 & 376.06 & 0.00 & 1.76 \\
\hline 0.9 & 150.31 & 0.12 & 0.11 & 274.83 & 0.05 & 0.18 & 370.83 & 0.00 & 0.34 \\
\hline
\end{tabular}

Comparison of bundling strategies for different starting inventory levels $\left(\mu_{1}=\mu_{2}=15, \sigma_{1}=\sigma_{2}=2\right)$ 
Table 8

Impact of the degree of contingency $\theta\left(\mu_{1}=\mu_{2}=15, \sigma_{1}=\sigma_{2}=2, Q_{1}=Q_{2}=15\right)$

\begin{tabular}{|c|c|c|c|c|c|c|c|c|c|c|c|}
\hline$\theta$ & $\rho$ & $p_{1}^{*}=p_{2}^{*}$ & $p_{\mathrm{b}}^{*}$ & $d$ & $E(R)$ & $E\left(n_{1}\right)=E\left(n_{2}\right)$ & $E\left(n_{\mathrm{b}}\right)$ & $\alpha_{1}=\alpha_{2}$ & $\alpha_{\mathrm{b}}$ & $\mu_{\mathrm{b}}$ & $\sigma_{\mathrm{b}}$ \\
\hline \multirow[t]{5}{*}{-0.10} & -0.9 & 15.50 & 26.25 & 4.75 & 270.00 & 4.02 & 5.54 & 0.25 & 0.42 & 27.00 & 0.80 \\
\hline & -0.5 & 15.00 & 26.00 & 4.00 & 262.73 & 4.00 & 5.48 & 0.23 & 0.39 & 27.00 & 1.80 \\
\hline & 0 & 14.75 & 25.75 & 3.75 & 257.92 & 3.10 & 6.46 & 0.18 & 0.46 & 27.00 & 2.55 \\
\hline & 0.5 & 14.25 & 25.75 & 2.75 & 254.15 & 3.39 & 6.11 & 0.20 & 0.43 & 27.00 & 3.12 \\
\hline & 0.9 & 14.00 & 25.75 & 2.25 & 251.10 & 2.65 & 6.86 & 0.14 & 0.47 & 27.00 & 3.51 \\
\hline \multirow[t]{5}{*}{0.00} & -0.9 & 27.25 & 29.25 & 22.25 & 290.10 & 0.00 & 9.92 & 0.00 & 0.80 & 30.00 & 0.89 \\
\hline & -0.5 & 16.00 & 28.75 & 3.25 & 283.57 & 1.48 & 8.21 & 0.08 & 0.63 & 30.00 & 2.00 \\
\hline & 0 & 15.50 & 28.50 & 2.50 & 279.64 & 1.23 & 8.47 & 0.06 & 0.63 & 30.00 & 2.83 \\
\hline & 0.5 & 15.25 & 28.50 & 2.00 & 276.84 & 0.72 & 8.94 & 0.03 & 0.63 & 30.00 & 3.46 \\
\hline & 0.9 & 14.75 & 28.50 & 1.00 & 274.83 & 0.27 & 9.36 & 0.01 & 0.64 & 30.00 & 3.90 \\
\hline \multirow[t]{5}{*}{0.10} & -0.9 & 23.25 & 32.25 & 14.25 & 319.16 & 0.00 & 9.90 & 0.00 & 0.78 & 33.00 & 0.98 \\
\hline & -0.5 & 25.75 & 31.75 & 19.75 & 311.33 & 0.00 & 9.81 & 0.00 & 0.72 & 33.00 & 2.20 \\
\hline & 0 & 19.75 & 31.50 & 8.00 & 306.81 & 0.00 & 9.74 & 0.00 & 0.69 & 33.00 & 3.11 \\
\hline & 0.5 & 17.75 & 31.00 & 4.50 & 303.03 & 0.00 & 9.65 & 0.00 & 0.70 & 33.00 & 3.81 \\
\hline & 0.9 & 15.75 & 31.50 & 0.00 & 302.16 & 0.00 & 9.59 & 0.00 & 0.64 & 33.00 & 4.29 \\
\hline
\end{tabular}

Table 9

Comparison of normal and gamma distributions for the reservation prices

\begin{tabular}{|c|c|c|c|c|c|c|c|}
\hline \multirow[t]{2}{*}{$\rho$} & \multicolumn{2}{|l|}{ Gamma } & \multicolumn{3}{|l|}{ Normal } & \multirow{2}{*}{$\frac{\mathrm{Gamma} / P_{N}}{\% \text { dev. }}$} & \multirow{2}{*}{$\begin{array}{l}\text { Normal } / P_{G} \\
\% \text { dev. }\end{array}$} \\
\hline & $\left(p_{1}^{*}, p_{2}^{*}, p_{\mathrm{b}}^{*}\right)$ & $E(R)$ & $\left(p_{1}^{*}, p_{2}^{*}, p_{\mathrm{b}}^{*}\right)$ & $E(R)$ & $\%$ dev. & & \\
\hline \multicolumn{8}{|c|}{$Q_{1}=Q_{2}=10$} \\
\hline-0.28125 & $(2.75,2.75,3.75)$ & 33.76 & $(2.75,2.75,4.25)$ & 38.24 & 13.26 & 5.83 & 2.24 \\
\hline 0 & $(2.75,2.75,3.75)$ & 32.90 & $(2.75,2.75,4.25)$ & 37.63 & 14.38 & 3.31 & 3.29 \\
\hline 0.28125 & $(2.75,2.75,4.00)$ & 32.17 & $(2.50,2.50,4.25)$ & 37.00 & 15.02 & 1.89 & 1.32 \\
\hline \multicolumn{8}{|c|}{$Q_{1}=Q_{2}=20$} \\
\hline-0.28125 & $(3.00,3.00,3.00)$ & 41.29 & $(2.75,2.75,3.50)$ & 45.60 & 10.45 & 5.62 & 2.57 \\
\hline 0 & $(3.00,3.00,3.00)$ & 38.68 & $(2.50,2.50,3.50)$ & 43.84 & 13.35 & 4.23 & 3.89 \\
\hline 0.28125 & $(2.50,2.50,3.25)$ & 36.06 & $(2.50,2.50,3.50)$ & 42.44 & 17.70 & 0.97 & 1.08 \\
\hline
\end{tabular}

ries given by $Q_{1}=Q_{2}=10$ and $Q_{1}=Q_{2}=20$. Three levels of correlation between reservation prices are considered which the bivariate gamma density allows: $\rho=$ $-0.28125,0,0.28125$. The results are presented in Table 9 .

In Table 9, the second and the third columns present the optimal prices and the corresponding expected revenue when the true distribution is gamma, and the fourth and fifth columns display similar results for the normal distribution. The sixth column presents the difference between the optimal revenues for the two models. The column gamma $/ P_{N}$ presents the percentage loss in the revenues when the sub-optimal prices of the normal model are used when in fact the true reservation price distribution is bivariate gamma and the last column indicates the similar loss when sub-optimal prices from gamma distribution are used when in fact true model is normal.

We observe that the revenues obtained with the normal distribution are higher than those with the right skewed gamma distribution and the difference increases with the correlation coefficient, reaching a maximum of $17.70 \%$. If the optimal prices obtained from normally distributed reservation prices are used when the actual reservation prices are gamma, the revenue may decrease up to $5.62 \%$. On the other hand, using the optimal prices of the gamma reserva- tion prices when the actual distribution is normal results in up to $3.89 \%$ revenue decrease. This indicates that an actual normal distribution is more robust to deviations from normality, whereas if the actual distribution is a skewed gamma and if this is ignored by employing a normal distribution, there may be significant revenue losses.

\section{Multi-period problem}

The single-period analysis of Section 2 can be extended to a case where the retailer updates the prices of the bundle and the individual products on a periodic basis. Let there be $K$ such periods. At the beginning of period $j$, the retailer can update the price of the bundle and the individual products based on the remaining inventory levels of the two products. These periods can be different in terms of their lengths $T_{j}$, customer arrival rates $\lambda_{j}$, joint reservation price distributions and the degrees of contingency. In certain cases, the future demand of a product or bundle can be a function of sales in the earlier periods due to word-ofmouth or a bandwagon effect. Our model does not capture such effects and assume that the arrival rates in different periods are independent of each other and exogenous to the problem. 
Let $\mathbf{p}_{\mathbf{j}}=\left(p_{j 1}, p_{j 2}, p_{j b}\right)$ denote the vector of prices charged for Products 1, 2 and the bundle in period $j$.

Let $V_{j}\left(Q_{j 1}, Q_{j 2}\right)$ be the optimal total expected revenue of the retailer for periods $j$ through $K$, if she starts period $j$ with $Q_{j 1}$ units of inventory of Product 1 and $Q_{j 2}$ units of inventory of Product 2 . Let $P_{j}\left(n_{1}, n_{2}, n_{\mathrm{b}} ; \mathbf{p}_{\mathrm{i}}\right)$ denote the sales probability of $n_{1}$ units of Product $1, n_{2}$ units of Product 2, and $n_{\mathrm{b}}$ units of the bundle in period $j$. These probabilities depend on the prices that are charged in period $j\left(\mathbf{p}_{\mathbf{j}}\right)$ as well as the specific parameters of the period $j$. We can formulate the problem using a dynamic programming approach. The backward recursion can be written as:

$$
\begin{aligned}
V_{j}\left(Q_{j 1}, Q_{j 2}\right)= & \max _{\mathbf{p}_{\mathrm{j}}} \sum_{n_{1}, n_{2}, n_{\mathrm{b}}} P_{j}\left(n_{1}, n_{2}, n_{\mathrm{b}} ; \mathbf{p}_{\mathbf{j}}\right)\left(p_{j 1} n_{1}+p_{j 2} n_{2}+p_{j b} n_{\mathrm{b}}\right. \\
& \left.+V_{j+1}\left(Q_{j 1}-n_{1}-n_{\mathrm{b}}, Q_{j 2}-n_{2}-n_{\mathrm{b}}\right)\right)
\end{aligned}
$$

where the boundary conditions are

$$
\begin{aligned}
& V_{K}\left(Q_{K 1}, Q_{K 2}\right)=\max _{\mathbf{p}_{\mathbf{K}}} \sum_{n_{1}, n_{2}, n_{\mathrm{b}}} P_{K}\left(n_{1}, n_{2}, n_{\mathrm{b}} ; \mathbf{p}_{\mathbf{K}}\right)\left(p_{K 1} n_{1}+p_{K 2} n_{2}+p_{K b} n_{\mathrm{b}}\right) \\
& V_{j}(0,0)=0 \forall j .
\end{aligned}
$$

The recursion in (2) states that in any given period $j$, the retailer is maximizing his expected revenues in the immediate period $j$ and the remainder of the horizon. If he sells $n_{1}, n_{2}, n_{\mathrm{b}}$ units of Product 1, Product 2 and the bundle in period $j$, she collects a revenue of $p_{j 1} n_{1}+p_{j 2} n_{2}+p_{j b} n_{\mathrm{b}}$ in period $j$ and ends the period with $Q_{j 1}-n_{1}-n_{\mathrm{b}}$ and $Q_{j 2}-n_{2}-n_{\mathrm{b}}$ units of inventory of Product 1 and Product 2 . The first boundary condition states that the last period problem is a single period problem as modeled in Section 2 . The second boundary condition states that future revenues are zero if both products run out of stock at any given period.

The retailer solves the problem $V_{1}\left(Q_{11}, Q_{12}\right)$ if the starting inventory levels are $Q_{11}$ and $Q_{12}$ for Product 1 and Product 2 at the start of planning horizon. The result is an optimal price for period 1 and optimal pricing policies (these policies are based on starting inventory levels) for periods $2,3, . ., K$.

\subsection{An example}

We use the base case that is used in Section 3 as an example for the case with two periods. The season starts with initial inventories $Q_{11}=10$ and $Q_{12}=10$ and the season of length $T=1$ is split into two equal periods, $T_{1}=0.5$ and $T_{2}=0.5$. The individual products are fixed at $p_{1}=p_{2}=15$ throughout the season. The other parameters are $\lambda_{1}=\lambda_{2}=20, \mu_{1}=\mu_{2}=15, \sigma_{1}=\sigma_{2}=2$ and $\theta=0$. The results are reported in Table 10 for different correlation values. We report the optimal expected revenue, optimal price of the bundle in the first period and expected price of the bundle in the second period (given that there remains positive inventory of both products) for the two period problem in columns 2,3 , and 4 , respectively. As before, expected revenues are higher when the correlation
Table 10

Comparison of two periods and single period problems

\begin{tabular}{lllllll}
\hline$\rho$ & \multicolumn{2}{l}{ Two periods } & & & \multicolumn{2}{l}{ Single period } \\
\cline { 2 - 3 } \cline { 7 - 8 } & $E(R)$ & $p_{1 b}^{*}$ & $E\left(p_{2 b}^{*}\right)$ & & $E(R)$ & $p_{\mathrm{b}}^{*}$ \\
\hline-0.9 & 285.57 & 28.75 & 28.56 & & 284.59 & 28.50 \\
-0.5 & 282.90 & 28.75 & 28.37 & & 281.51 & 28.50 \\
0 & 280.78 & 28.75 & 28.38 & & 279.02 & 28.50 \\
0.5 & 279.00 & 29.00 & 28.36 & & 276.81 & 28.50 \\
0.9 & 277.50 & 29.25 & 28.27 & & 274.75 & 28.50 \\
\hline
\end{tabular}

is smaller. The first period optimal price is always higher than the expected second period price, showing that the retailer would like to test a higher price initially given that she has an opportunity to mark the price down later in the season. Table 10 also reports the solution of the single period problem (the season is a single period with $T=1$ ) which is already discussed in Table 5. Clearly, expected revenues of the two period case are higher than the expected revenues of the single period case. We see that a second pricing opportunity has more value when the reservation prices are positively correlated. This is expected since the reservation price of the bundle has higher variance in this case and a second period gives the retailer a second chance after resolving some uncertainty regarding the arrival process and the reservation prices. This is in contrast to the case where the reservation prices are negatively correlated. In this case, the bundle reservation price has a very small variance, and the second period helps only to resolve a portion of the uncertainty regarding the arrival process. Also note that the first period bundle price in the two period problem is always higher than the bundle price in the single period problem. One interesting case is when $\rho=-0.9$. In this case, the (expected) bundle prices in two periods are higher than the bundle price of the single period problem.

Next, we conducted the following study in order to understand how effective bundling is in a dynamic pricing setting. In the first period, the product prices are set to 15 and no bundles are offered. In the second period, the retailer acts according to one of the three scenarios. In the first scenario, the retailer still does not offer any bundle in the second period, but changes the individual product prices based on the realization of demand. This is a simple pricing scenario where the products are individually priced. In the second scenario, the retailer offers the bundle and prices it optimally, but does not change the prices of the individual products. This is a scenario in which the retailer is perhaps offering a price guarantee (or a price promise) and is reluctant to change the prices of individual products. Such price guarantees require the retailer to reimburse his customer the price difference, if he reduces the price after the purchase. Price guarantees are often used by retailers to stop strategic behavior among customers and to encourage them to purchase early. Examples of companies offering price guarantees include the low cost airline EasyJet (The Daily Telegraph 2005) and the cruise line Norwegian Coastal Voyage (Travel Trade Gazette 2005). In the third 
Table 11

Effectiveness of bundling in dynamic pricing

\begin{tabular}{|c|c|c|c|c|c|c|c|}
\hline \multirow[t]{2}{*}{$\rho$} & \multicolumn{2}{|c|}{ No bundles } & \multicolumn{2}{|c|}{ Product prices fixed } & \multicolumn{3}{|c|}{ All prices optimized } \\
\hline & $E(R)$ & $E\left(p_{21}^{*}\right)=E\left(p_{22}^{*}\right)$ & $\mathrm{E}(\mathrm{R})$ & $E\left(p_{2 b}^{*}\right)$ & $\mathrm{E}(\mathrm{R})$ & $E\left(p_{21}^{*}\right)=E\left(p_{22}^{*}\right)$ & $E\left(p_{2 b}^{*}\right)$ \\
\hline-0.9 & 272.360 & 14.028 & 279.263 & 26.355 & 280.672 & 20.000 & 27.016 \\
\hline-0.5 & 273.069 & 14.043 & 278.363 & 26.212 & 279.768 & 19.563 & 26.155 \\
\hline 0 & 273.755 & 14.038 & 277.253 & 26.262 & 278.652 & 19.211 & 24.990 \\
\hline 0.5 & 274.379 & 14.036 & 276.219 & 26.414 & 277.614 & 18.635 & 24.002 \\
\hline 0.9 & 275.199 & 14.039 & 275.707 & 26.620 & 277.099 & 18.200 & 23.563 \\
\hline
\end{tabular}

scenario, the retailer has the flexibility to offer the bundle as well as change the prices of the individual products in the second period. The results are presented in Table 11 . Expected revenue in each scenario denotes the total expected revenue obtained in two periods. The results show that offering the bundle in the second period is more effective in generating revenue than updating the individual product prices. The difference can be significant when the product reservation prices are negatively correlated. Obviously, the flexibility of changing the individual product prices in addition to offering a bundle option further increases revenues. However, the additional benefits are smaller. We conclude that offering price bundles can be an important alternative to dynamic pricing of individual products.

\section{Conclusion}

In this study, we consider the optimal bundle pricing policy of a retailer with two perishable products with the objective of maximizing the revenue. We assume that the retailer adopts a mixed bundling strategy where the two products can be sold separately or as a bundle. The two products are available in limited quantities and there is no replenishment opportunity during the planning horizon. Customers arrive at the retailer according to a Poisson Process and their purchase probabilities are governed by the reservation prices. The bundle reservation price can be additive, subadditive or superadditive, the last two of which reflect the substitutability and complementarity of the products, respectively. An exact expression is derived for the expected profit of the selling horizon and is maximized with respect to the prices of the products and the bundle using numerical methods. A numerical study is conducted to investigate the impact of the initial inventory levels, covariance of the reservation prices, substitutability and complementarity on the optimal prices and the resulting optimal revenues. Furthermore, the comparison among unbundling, mixed and pure bundling strategies are also provided.

Our numerical results indicate that the performances of the policies heavily depend on the parameters of the demand process and the initial inventory levels. Bundling is observed to be most effective with negatively correlated reservation prices and when the supply quantities are large. It is also observed that the mixed bundling and pure bundling strategies perform similarly when the supply quantities are large and equal; however, the mixed bundling strategy provides significant savings over pure bundling when the supply quantities are unequal. Our numerical results also show that bundling becomes more effective as the degree of contingency increases (products become less substitutable and more complementary). By employing a bivariate gamma distribution for the reservation prices, we also show that the shape of this distribution is important and using sub-optimal prices resulting from assumed normal reservation prices, when in fact the bivariate gamma better fits the actual distribution may result in significant losses especially for negatively correlated reservation prices. This observation seems to have important managerial implications and is worth further study. Based on our analysis with constant product and bundle prices throughout the selling season, we also provided an extension of our model to allow for price changes in a multi-period setting using a dynamic programming formulation. Using a two-period numerical example, it is shown that offering price bundles mid-season could be an effective alternative to updating individual product prices.

A worthy but complex extension of our work could be the integration of actions of the competitors in pricing decisions. Our model assumes that the inventory decisions are already made, the retailer has no other costs, and he is maximizing his expected revenue over a selling season. Extensions of our model to incorporate initial inventory levels as additional decision variables and to incorporate the variable cost of selling a product and/or forming a bundle are possible. Using the extended model, additional insights can be gained and comparative performances of different bundling strategies can be investigated through further numerical studies. One may also consider a price change at a time when one of the products depletes. In this case, a cost for price changes could also be considered. Finally, the multi-period model can be extended to allow the retailer to replenish product inventories periodically.

\section{References}

Adams, W.J., Yellen, J.L., 1976. Commodity bundling and the burden of monopoly. Quarterly Journal of Economics. 90, 475-498.

Ansari, A., Siddarth, S., Weinberg, C.B., 1996. Pricing a bundle of products or services: The case of nonprofits. Journal of Marketing Research. 33, 86-93. 
Bakos, Y., Brynjolfsson, E., 1999. Bundling information goods: Pricing, profits, and efficiency. Management Science 45, 1613-1630.

Ben-Akiva, M., Gershenfeld, S., 1998. Multi-featured products and services: Analysing pricing and bundling strategies. Journal of Forecasting 17, 175-196.

Bulut, Z., Gürler, Ü., Şen, A., 2006. Bundle pricing of inventories with stochastic demand. Working Paper, Bilkent University, Department of Industrial Engineering. <http://www.bilkent.edu.tr/ alpersen/Papers/ Bundling_Bulut_Gurler_Sen_WP_2006.pdf $>$.

Carbajo, J., de Meza, D., Seidmann, J.D., 1990. A strategic motivation for commodity bundling. The Journal of Industrial Economics 38, 283298.

D’Este, G.M., 1981. A morgenstern-type bivariate gamma distribution. Biometrika 68, 339-340.

E-tailing Group, Inc., 2004. 4Q 04 merchandising scan. <http://www.etailing.com/research/merchandisingscan/2004/summary.html >.

Elmaghraby, W., Keskinocak, P., 2003. Dynamic pricing in the presence of inventory considerations: Research overview, current practices, and future directions. Management Science 49, 1287-1309.

Ernst, R., Kouvelis, P., 1999. The effects of selling packaged goods on inventory decisions. Management Science 45, 1142-1155.

Gallego, G., van Ryzin, G., 1997. A multiproduct dynamic pricing problem and its applications to network yield management. Operations Research 45 (1), 24-41.

Guiltinan, J.P., 1987. The price bundling of services: A normative framework. Journal of Marketing 51 (2), 74-85.

Hanson, W.A., Martin, R.K., 1990. Optimal bundle pricing. Management Science 36 (2), 155-174.

Jedidi, K., Jagpal, S., Manchanda, P., 2003. Measuring heterogeneous reservation prices for product bundles. Marketing Science 22 (1), 107 130 .

Jedidi, K., Zhang, Z.J., 2002. Augmenting conjoint analysis to estimate consumer reservation price. Management Science 48 (10), 1350-1368.
Jeuland, A., 1984. Comments on "Gaussian demand and commodity bundling". Journal of Business 57 (1), 230-235.

Long, J.B., 1984. Comments on "Gaussian demand and commodity bundling". Journal of Business 57 (1), 235-246.

Mahajan, S., van Ryzin, G., 2001. Stocking retail assortments under dynamic consumer substitution. Operations Research 49 (3), 334-351.

McAfee, R.P., McMillan, J., Whinston, M.D., 1989. Multiproduct monopoly, commodity bundling, and correlation of values. Quarterly Journal of Economics 104, 371-383.

McGill, J.I., van Ryzin, G.J., 1999. Revenue management: Research overview and prospects. Transportation Science 33 (2), 233-256.

Nalebuff, B., 2003. Bundling, tying, and portfolio effect. Part I: Conceptual issues. Tech. report, Department of Trade and Industry, London, United Kingdom.

Netessine, S., Savin, S., Xiao, W., 2006. Revenue management through dynamic cross-selling in e-commerce retailing. Operations Research 54 (5), 893-913.

Salinger, M.A., 1995. A graphical analysis of bundling. Journal of Business 68 (1), 85-98.

Schmalensee, R., 1984. Gaussian demand and commodity bundling. Journal of Business 57 (1), 211-230.

Stigler, G.J., 1963. United States v. Loew's Ink: A note on block booking. Supreme Court Review, 152.

Stremersch, S., Tellis, G.J., 2002. Strategic bundling of products and prices: A new synthesis for marketing. Journal of Marketing 66, 55-72.

Talluri, K., van Ryzin, G., 2004. The Theory and Practice of Revenue Management. Kluwer Academic Publishers.

van Ryzin, G., Mahajan, S., 1999. On the relationship between inventory costs and variety benefits in retail assortments. Management Science 45 (11), 1496-1509.

Venkatesh, R., Kamakura, W., 2003. Optimal bundling and pricing under a monopoly: Contrasting complements and substitutes from independently valued products. Journal of Business 76 (2), 211-231. 